\section{CMAJ's 100th anniversary}

I was delighted to see in the Jan. 11 issue of CMAJ not only a dedicated cover but also several pertinent articles celebrating the 100th anniversary of CMAJ. ${ }^{1-3}$ The cover photo of Sir William Osler is incredible. I wonder how many of the students in that amphitheatre can be identified?

Special thanks are owed to Cindy L. Stelmackowich, who discovered and submitted the cover photo of Osler teaching students at a clinic at the Royal Victoria Hospital in Montréal in 1906.

To date, although we have seen a number of incredibly outstanding Canadian researchers and physicians, no one has really replaced Sir William on an international basis. What a legacy!

\section{Richard U. Johnston MD}

Orillia, Ont.

\section{References}

1. Hébert PC, Flegel K, Stanbrook MS, et al. CMAJ at 100: our voice, our future. CMAJ 2011;183:15.

2. Turnbull J. 100 years and counting. CMAJ 2011; 183:16.

3. Gray C. CMAJ's century reflects a profession and a country. CMAJ 2011;183:17-21.

CMAJ 2011. DOI:10.1503/cmaj.111-2024

\section{Osteoporosis guidelines miss big picture}

Infants, all with low bone density, don't break bones. The bones bend, because the structural component is mainly collagen I and III, "ropes" along which bone mineral builds and rebuilds after osteoclasts remove bone with microcracks. The authors of the recently published guidelines suggest that they no longer focus on treating bone mineral density, but that is exactly what they do, as per their specified pharmacologic-based search-andexclusion criteria. ${ }^{1}$

Apart from welcome references to the calcium management prohormone vitamin $\mathrm{D}_{3}$ (up to $2000 \mathrm{IU} / \mathrm{d}$ requires no monitoring), the emphasis is on bisphonates, a class of drug that "disables" osteoclasts, thereby mimicking their terrible role in osteopetrosis. ${ }^{2}$
Obviously, bone density affects spinal compression fractures (that are $80 \%$ asymptomatic); however, simply increasing density may make bones more brittle unless the toughness factor, collagen, is simultaneously improved. The absence of annual "numbers needed to treat" in the guidelines for spine and particularly hip fractures from bisphosphonates is especially disturbing.

Largely excluded from the search criteria are the word collagen and any of the vitamins and minerals that affect and control collagen synthesis and quality (vitamin $\mathrm{C}$, the homocysteinelowering $\mathrm{B}$ vitamins $\mathrm{B}_{2}, \mathrm{~B}_{6}, \mathrm{~B}_{9}$ [folate], $\mathrm{B}_{12}$, copper and iron). ${ }^{1}$ Several of these vitamins (and homocysteine levels that are needlessly high because of low vitamin intake) are risk factors for fracture. For example, a placebo-controlled homocysteine-lowering study using only two B vitamins found an $80 \%$ reduction in hip fractures in two years, likely as a result of improved collagen quality since bone density and falls were identical. ${ }^{3}$

The guidelines need to be expanded: the focus on just bone density misses an important part of the picture.

\section{Eddie Vos MEng}

Sutton, Que.

\section{References}

1. Papaioannou A, Morin S, Cheung AM, et al. 2010 clinical practice guidelines for the diagnosis and management of osteoporosis in Canada. CMAJ 2010:182;1964-73.

2. Marini JC. Do bisphosphonates make children's bones better or brittle? N Engl J Med 2003;349:423-6.

3. Sato Y, Honda Y, Iwamoto J, et al. Effect of folate and mecobalamin on hip fractures in patients with stroke. A randomized controlled trial. JAMA 2005; 293:1082-8.

\section{CMAJ 2011. DOI:10.1503/cmaj.111-2031}

Papaioannou and colleagues stated that bisphosphonates reduced "the risk of vertebral fracture by $30 \%$ to $70 \%$, depending on the agent and level of adherence." This statement does not provide enough information for one to make informed decisions about oral bisphosphonate use.

First, the statement only recognizes fractures in the vertebra, not other sites, including nonvertebra and the hip. Some oral bisphosphonates provide benefits to some sites but not others. The updated 2010 Cochrane reviews of oral bisphosphonates provide information about site-specific fracture prevention. ${ }^{2-4}$ The guidelines do not present data from these reviews.

Second, the recommendations to use bisphosphonates to prevent fractures do not differentiate between primary and secondary prevention. According to the Cochrane reviews, neither etidronate nor risedronate has shown benefits in primary prevention. ${ }^{3,4}$ Alendronate is the only oral bisphosphonate that seems to have some benefit in primary prevention with respect to vertebral fractures. ${ }^{2}$ However, the reduction was found for only radiographic vertebral but not clinical vertebral fractures. ${ }^{5}$ Therefore, the clinical importance of this result is debatable.

Finally, the magnitude of fracture reduction is presented in relative terms instead of absolute risk reductions. Oral bisphosphonates do not lead to a reduction in clinical fractures for primary prevention. ${ }^{2-4}$ For secondary prevention, oral bisphosphonates reduce the risk of hip fracture by about $1 \%,{ }^{2,4}$ nonvertebral fracture by about $2 \%$ and vertebral fracture by about $6 \% .^{2-4}$ The recommendations for pharmacologic therapy should include this information.

Aaron M. Tejani BSc(Pharm) PharmD Coordinator, Clinical Research and Drug Information, Fraser Health; Pharmacy services researcher, Drug Assessment Working Group, Therapeutics Initiative, Vancouver, BC

\section{References}

1. Papaioannou A, Morin S, Cheung AM, et al. 2010 clinical practice guidelines for the diagnosis and management of osteoporosis in Canada. CMAJ 2010:182;1964-73.

2. Wells GA, Cranney A, Peterson J, et al. Etidronate for the primary and secondary prevention of osteoporotic fractures in postmenopausa women. Cochrane Database Syst Rev 2008;(1): CD001155.

3. Wells GA, Cranney A, Peterson J, et al. Etidronate for the primary and secondary prevention of osteoporotic fractures in postmenopausal women. Cochrane Database Syst Rev 2008;(1):CD003376.

4. Wells GA, Cranney A, Peterson J, et al. Risedronate for the primary and secondary prevention of osteoporotic fractures in postmenopausal women. Cochrane Database Syst Rev 2008;(1) CD004523. 